\title{
Identification of genes involved in VEGF-mediated vascular morphogenesis using embryonic stem cell-derived cystic embryoid bodies
}

\author{
Yin-Shan $\mathrm{Ng}^{1,2, *}$, Markus Ramsauer ${ }^{1,2}$, Robyn MB Loureiro ${ }^{1,2}$ and Patricia A D’Amore ${ }^{1,2}$ \\ ${ }^{1}$ Department of Ophthalmology and ${ }^{2}$ Department of Pathology, Harvard Medical School and Schepens Eye \\ Research Institute, Boston, MA, USA
}

\begin{abstract}
The vasculature forms during development via two processes, vasculogenesis and angiogenesis, in which vessels form de novo from angioblast precursors or as sprouts from pre-existing vessels, respectively. A common and critical aspect of both processes is vascular morphogenesis, which includes branching of endothelial cell cords and lumen formation. Although ample evidence support the central role of vascular endothelial growth factor (VEGF) in both vasculogenesis and angiogenesis, the role of VEGF in vascular morphogenesis is unclear and little is known about the regulation of vascular morphogenesis, in general. We have used the in vitro vessel differentiation system of embryonic stem (ES) cell-derived cystic embryonic bodies (CEB) as a model for studying VEGF-mediated vessel formation. Whereas CEB formed from wild-type ES cells make well-formed vessel-like structures, CEB derived from VEGF-null ES cells contain PECAM-1-positive endothelial cells, but these cells do not participate in vascular morphogenesis. Using gene expression microarray analysis to compare gene expression in these two systems, we have been able to identify many genes and novel ESTs that are downstream of VEGF function, and which may be involved in VEGF-mediated vascular morphogenesis including caveolin-1 and HEY-1. These results support using the CEB model, in combination with gene knockout ES cells, for studying vascular morphogenesis.
\end{abstract}

Laboratory Investigation (2004) 84, 1209-1218, advance online publication, 28 June 2004; doi:10.1038/labinvest.3700150

Keywords: lumen; vasculogenesis; angiogenesis; differentiation; sprouting; microarray; branching

Vessel formation involves several well-controlled steps including the differentiation of angioblasts to endothelial cells (EC) and proliferation of EC, followed by the migration and subsequent coalescence of EC to form vascular networks and channels. Despite the identification of the various EC-specific growth factors and receptors that are important for vessel formation, the molecular mechanism of vessel morphogenesis remains unclear. Convincing data indicate a central role for vascular endothelial growth factor (VEGF) in both vasculogenesis and angiogenesis. ${ }^{1,2}$ Furthermore, it has been reported that although differentiation of EC is normal in mice that lack $V E G F$, vessel formation is

Correspondence: Dr PA D’Amore, PhD, Schepens Eye Research Institute, 20 Staniford St., Boston, MA 02114, USA.

E-mail: pdamore@vision.eri.harvard.edu

${ }^{*}$ Currently at Eyetech Pharmaceuticals, Inc., 42 Cummings Park, Woburn, MA 01804, USA.

Received 20 April 2004; revised 1 June 2004; accepted 2 June 2004; published online 28 June 2004 disrupted. This result indicates that VEGF also plays a role in vascular morphogenesis in vivo.

Investigation of vessel morphogenesis by EC has been hindered by the lack of a suitable in vitro model system. Several in vitro models of vessel formation using extracellular matrix components, including Matrigel $^{\mathrm{TM}}$, are limited by the fact that vessel formation is transient. ${ }^{3,4}$ Furthermore, the vascular channels in these in vitro systems lack the appropriate heterotypic cell-cell and cell-matrix interactions, which appear to be critical for normal vessel formation and stability in vivo.

Murine embryonic stem (ES) cells are totipotent cells derived from the inner cell mass of mouse blastocysts. ${ }^{5,6}$ In the absence of a feeder layer or leukemia inhibitory factor (LIF), and after aggregation in suspension culture, ES cells spontaneously differentiate into embryo-like structures called cystic embryoid bodies (CEB). Aggregation and differentiation of ES cells to CEB recapitulates the processes of early embryogenesis such as hematopoiesis, neurogenesis, cardiogenesis, vasculogenesis 
and angiogenesis. ${ }^{7,8}$ Of particular interest is the formation of vessels in CEB via vasculogenesis and angiogenesis, which mimics the development of the embryonic yolk sac vasculature. ${ }^{9-11}$ Since the formation of vessels in the CEB appears to recapitulate all the essential processes of vessel development in vivo, including heterotypic cell-cell interactions, cell-matrix interactions, and actions of different cytokines and growth factors, the CEB model represents the best available in vitro model system for the study of vascular development. In addition to the advantages provided by an in vitro system, the CEB system offers the opportunity for genetic manipulations.

We used the CEB system to examine the role of VEGF in vascular development. Our results indicate that the expression of VEGF is highly regulated during CEB differentiation. Furthermore, similar to observations of $V E G F$-null mice, EC in CEB formed from VEGF-null ES cells fail to organize into networks and channels. In order to study the molecular mechanism(s) of VEGF-mediated vascular morphogenesis, gene expression microarray (GEM) screening was used to identify genes that are differentially expressed between CEB formed from $V E G F$-deficient ES cells in which EC fail to undergo normal vessel morphogenesis and CEB formed from wildtype (wt) ES cells in which normal vessel-like structures are formed. GEM screening results identified several EC-specific and EC-selective genes that have been previously implicated in vascular morphogenesis, as well as numerous novel ESTs. These results suggest that the CEB model is well suited for identifying genes in VEGF-mediated vascular morphogenesis. Furthermore, the use of available gene knockout ES cell clones in this CEB model may greatly facilitate the identification of novel genes that are downstream from genes known to be important to vascular morphogenesis and development.

\section{Materials and methods}

\section{ES Cell Culture and CEB Differentiation}

R1 wt, $V E G F^{-1-}$ and the $V E G F^{\mathrm{LacZ} /+}$ ES cells were generously provided by Dr Andras Nagy (Mount Sinai Hospital, Toronto, Canada) and Dr Peter Carmeliet (Flanders Interuniversity Institute for Biotechnology, Leuven, Belgium); fibroblast growth factor receptor $-1^{-1-}\left(F G F R-1^{-1-}\right)$ ES cells by Drs Philip Leder and Chuxia Deng (Harvard Medical School, Boston, MA, USA) and GATA-4 ${ }^{-1-}$ ES cells by Dr David Wilson (Washington University, St. Louis, MO, USA). All ES cells were cultured on gelatin-coated dishes in high-glucose Dulbecco's modified Eagle's medium (DMEM, GIBCO BRL, Grand Island, NY, USA) with $15 \%$ fetal bovine serum (Hyclone, UT, USA), sodium pyruvate (GIBCO, stock solution diluted 1:100), nonessential amino acids (GIBCO, stock solution diluted 1:100), $\beta$-mercaptoethanol (GIBCO, final concentration $30 \mu \mathrm{M}), 190 \mu \mathrm{g} / \mathrm{ml}$ of L-glutamine, $60 \mathrm{U} / \mathrm{ml}$ of penicillin $\mathrm{G}, 60 \mu \mathrm{g} / \mathrm{ml}$ of streptomycin (glutamine penstrep mix, Irvine Scientific, Santa Ana, CA, USA), supplemented with media (1:300 dilution) conditioned by Chinese hamster ovary cells overexpressing LIF (provided by Genetics Institute, Cambridge, MA, USA) as a source of LIF to maintain the ES cells in an undifferentiated state. ES cells were cultured in a humidified tissue culture incubator at $10 \% \mathrm{CO}_{2}$ and $37^{\circ} \mathrm{C}$, and passaged every $2-3$ days.

To differentiate ES cells into CEB, trypsinized ES cells were suspended in the same culture medium as described above, but without LIF. A total of 60 aliquots $(30 \mu \mathrm{l})$ of ES cell suspension containing $2.5 \times 10^{3}$ cells were plated as individual drops onto $100 \mathrm{~mm}^{2}$ bacteriological dishes (Valmark Inc., Canada). The plates were then gently inverted and the cells were incubated in 'hanging drops'; this is defined as day 0 of the differentiation. The CEB were cultivated in this 'hanging drop' for $40-45 \mathrm{~h}$, and then the dishes were turned right side up and flooded with $10 \mathrm{ml}$ of ES culture media without LIF so that the CEB were then in suspension. (Note, therefore, that day 1 CEB were still in the 'hanging drop' when harvested.) Every 3 days, half of the culture media was removed and replaced with fresh media. Since the surface of the bacterial plastic prevents attachment, CEB cultured in the dishes remain in suspension. For 'attached cultures', day 4 or day 5 CEB were transferred to gelatin-coated tissue culture plates or gelatin-coated cover glasses, onto which the CEB attached, flattened and spread. In some experiments, the attached CEB were treated with VEGF164 or bFGF (R\&D systems, Inc. Minneapolis, MN, USA) at the concentrations and time indicated.

\section{Immunohistochemistry and $\beta$-galactosidase ( $\beta$-gal) Staining}

To visualize EC and VEGF-LacZ expression, whole mounts of CEB were stained for PECAM- 1 and $\beta$-gal, respectively. Attached CEB were fixed in $4 \%$ paraformaldehyde in PBS at room temperature for $10 \mathrm{~min}$, followed by three 5 -min washes with PBS at room temperature. $\beta$-Gal staining was then performed using the in situ $\beta$-gal staining kit (Stratagene, La Jolla, CA, USA) according to the manufacturer's protocol. After staining, the CEB were postfixed with $4 \%$ paraformaldehyde at $4^{\circ} \mathrm{C}$ for $12 \mathrm{~min}$ and washed three times for $5 \mathrm{~min}$ in phosphate-buffered saline (PBS) at room temperature. The $\beta$-gal-stained CEB were double-stained for PECAM- 1 by incubating in $0.5 \% \mathrm{H}_{2} \mathrm{O}_{2}$ in PBS for $40 \mathrm{~min}$, followed by three 5-min PBS washes, all at room temperature. The CEB were permeabilized in $0.3 \%$ Triton-X in PBS for 10 min, washed with PBS three times for $5 \mathrm{~min}$, and then incubated in $10 \%$ rabbit serum in PBS for $30 \mathrm{~min}$ for blocking. The 
CEB were then incubated in the rat anti-mouse PECAM-1 antibodies (PharMingen, San Diego, CA, USA) (1:400 in $3 \%$ rabbit serum in $\mathrm{PBS})$ at $4^{\circ} \mathrm{C}$ overnight, followed by two 5-min washes with PBS and one wash with $3 \%$ rabbit serum in PBS. The CEB were incubated in the secondary biotinylated rabbit anti-rat IgG, mouse absorbed antibodies (Vector Laboratories, Burlingame, CA, USA) (1:400 in $3 \%$ rabbit serum in $\mathrm{PBS}$ ) for $30 \mathrm{~min}$. After two PBS washes, the PECAM-1 staining was visualized using the Vectastain Elite ABC kit (Vector Laboratories) and the chromagen diaminobenzidine (DAB) (Research Genetics, Huntsville, AL, USA). The staining reactions were terminated by two water washes. For fluorescent detection of PECAM-1 staining, the secondary antibody used was Cy3conjugated donkey anti-rat IgG (PharMingen, San Diego, CA, USA).

Immunofluorescent staining of whole-mount CEB for caveolin-1 and endomucin was performed essentially as that for PECAM-1 using the rabbit polyclonal anti-mouse caveolin-1 antibody (Santa Cruz Biotechnology; N-20, 1:50 dilution) and the monoclonal rat anti-mouse endomucin antibody $(1: 2$ diluted) (a gift from Dr Dietmar Vestweber, Institute of Cell Biology, University of Muenster, Muenster, Germany). Fluroscein isothiocyanate (FITC)-conjugated donkey anti-rabbit and FITC-conjugated donkey anti-rat secondary antibodies (from Jackson Immuno Research) were used as secondary antisera for the caveolin-1 and endomucin-1 staining, respectively.

For PECAM-1 staining of paraffin-embedded sections, CEB in suspension culture were fixed in $4 \%$ paraformaldehyde in PBS at room temperature for $3 \mathrm{~h}$. The fixed embryonic bodies were then collected in a small bag of nylon mesh (Tetko, 3-300/50) to facilitate handling and were dehydrated and impregnated overnight using an automatic tissue processor (TissueTek, Naperville, IL, USA), then embedded in paraffin and sectioned by standard techniques. The CEB sections were washed four times for $5 \mathrm{~min}$ each with xylene to remove the paraffin and rehydrated by two 5-min water/ethanol washes (100\% ethanol, 95\% ethanol in water, $90 \%$ ethanol in water, and finally water alone). The rehydrated $\mathrm{CEB}$ sections were treated with $0.5 \%$ $\mathrm{H}_{2} \mathrm{O}_{2}$ in PBS and the PECAM-1 staining was performed as described above for the attached whole-mount CEB.

\section{RNA Isolation and Northern Blot Analysis}

Total RNA was isolated from CEB using RNAzol B (Tel-Test, Inc., Friendswood, TX, USA), according to the manufacturer's instructions. Northern blot analysis was performed with $15 \mu \mathrm{g}$ of total RNA per CEB sample using standard techniques. Prehybridization of the membrane was accomplished according to the manufacturer's protocol for GeneScreen Plus mem- brane (DuPont NEN). Hybridization was carried out by adding ${ }^{32} \mathrm{P}$-mouse VEGF164 complementary DNA (cDNA) probe (final $1.5 \times 10^{6} \mathrm{cpm} / \mathrm{ml}$ ) to the prehybridization solution. The membrane was then hybridized at $42^{\circ} \mathrm{C}$ overnight, washed and exposed to film. Differences in RNA loading were normalized by rehybridizing the stripped membrane with a ${ }^{32} \mathrm{P}-$ labeled murine glyceraldehyde-3-phosphate dehydrogenase (GAPDH) probe. For the analysis of VEGF messenger RNA (mRNA) stability in differentiating CEB, CEB that had been differentiated for varying times were incubated in culture media containing actinomycin $\mathrm{D}(5 \mu \mathrm{g} / \mathrm{ml})$ for $0-8 \mathrm{~h}$ under standard culture conditions. CEB were harvested at $0,2,4$ and $8 \mathrm{~h}$ after actinomycin D addition for RNA extraction using RNAzol B as described above.

\section{Reverse-Transcription and Polymerase Chain Reaction (RT-PCR)}

cDNA synthesis by reverse-transcription was performed using SuperScript II reverse transcriptase (Gibco BRL, Gaithersburg, MD, USA), according to standard protocol. ${ }^{12}$ Briefly, $1 \mu \mathrm{g}$ of total RNA was reverse-transcribed with $30 \mathrm{pmol}$ of oligo (dT-17) primers and $1 \mathrm{mM}$ of each nucleotide (dGTP, dATP, dTTP, dCTP) at $42^{\circ} \mathrm{C}$ for $1 \mathrm{~h}$. The resulting cDNA was subjected to RNase $\mathrm{H}$ digestion at $37^{\circ} \mathrm{C}$ for $30 \mathrm{~min}$ before PCR. PCR was carried out using the 'hot-start' technique $^{12}$ using $5 \mu \mathrm{l}(25 \%)$ of the cDNA reaction with $50 \mathrm{pmol}$ each of the primer sets:

VEGFR2: (5'AGGATGGAGAGCAAGGCGCTGCTA3' and

5'GAGACTTTGAAGGTGGAGAGTGCCA3'),

Caveolin-1 $\alpha$ : (5'CTGCAGCCAGCCACGCGCCACGAT GTCT $3^{\prime}$ and

5'AGGGGGGAAAAAACCTTTCATCCTTGAAAT3'), Caveolin-1 $\beta$ : (5'CTACAAGCCCAACAACAAGGCC ATGGCA $3^{\prime}$ and

5'AGGGGGGAAAAAACCTTTCATCCTTGAAAT3'), Hey-1: (5'ACTGGAGAGCACTGGCTCTCTCTCTGC $\mathrm{C} 3^{\prime}$ and

5'TACCTTCTAAAGGGGTAAGCCTGTAAAACA3'), Endomucin-1: (5'CTATGAAAATAACAGTGCCAAA TACTCCAA $3^{\prime}$ and

5'AGGATCCATCACGATGTCAGTTCTTGGTTT3').

\section{mRNA Isolation and Microarray Analysis}

To isolate mRNA, the Oligotex mRNA kit (Qiagen Inc., Santa Clarita, CA, USA) was used according to the manufacturer's instructions. To obtain sufficient mRNA for the GEM screening from day 10 CEB, four dishes of CEB (total of $4 \times 60=240$ CEB) were used. Furthermore, 240 CEB represent a large enough sample number to compensate for individual variation among the differentiating CEB. The resulting mRNA samples from day 10 normal and $V E G F$-null CEB were used in the mouse GEM screening by 
Incyte Inc. (Palo Alto, CA, USA) through the Harvard Center for Genomic Research. Briefly, the two groups of isolated mRNA were reverse transcribed with 5' Cy3- and Cy5-labeled random nanomers (Operon Technologies, Inc., Alameda, CA, USA), respectively, to generate fluorescent labeled cDNA probes with two different colors. The two fluorescent probe samples from normal and $V E G F$-null CEB were then simultaneously hybridized to a single microarray, mouse GEM2 (Incyte Inc., Palo Alto, CA, USA). After hybridization, the GEM microarray was scanned to detect both the Cy3 and Cy5 fluorescence simultaneously. Since the intensity of the fluorescence is proportional to the expression levels of the genes, the ratio of the two fluorescent intensities represent the relative gene expression level in the two CEB samples. Using the Incyte GEMtool software (Incyte, Inc., Palo Alto, CA, USA), the differences in fluorescent intensities were converted to differential gene expression ratios. Lastly, the differentially expressed genes were identified either as known cDNA clones or as ESTs.

\section{Results}

\section{VEGF is Required for Vessel Formation in CEB}

Wt ES cells aggregated to form CEB and stained with anti-PECAM-1 to detect EC revealed vascular networks as early as day 10 of differentiation (Figure2 and data not shown). Extensive vascular networks (Figure 1a) and channels (Figure 1b) were formed in the CEB by day 20 of differentiation. However, when $V E G F$-null ES cells were aggregated to form CEB, no PECAM-1-positive vascular structures were observed (Figure 2, top right panel). PECAM-1-positive EC in $V E G F$-null CEB failed to assemble into recognizable vessel-like structures, and instead remained dispersed up to 28 days (data not shown). Addition of VEGF, but not FGF-2 (bFGF), partially rescued the formation of vascular networks and channels in the VEGF-null CEB (Figure 2, bottom panels). Addition of bFGF to the VEGF-null CEB clearly resulted in increased EC proliferation, leading to the formation of larger cell clusters (Figure 2, bottom panels).

\section{VEGF Expression in Differentiating CEB}

Since these observations indicated that, as for the in vivo situation, VEGF is required for vessel formation in the CEB, expression of VEGF mRNA during CEB differentiation was examined by Northern blot analysis (Figure 3a). Results of this analysis revealed that VEGF mRNA was first detectable in differentiating CEB on day 3 but was dramatically increased by day 4 of CEB differentiation. The levels of VEGF mRNA increased steadily from day 4 to day 9 of CEB differentiation (Figure 3b). Similar results were

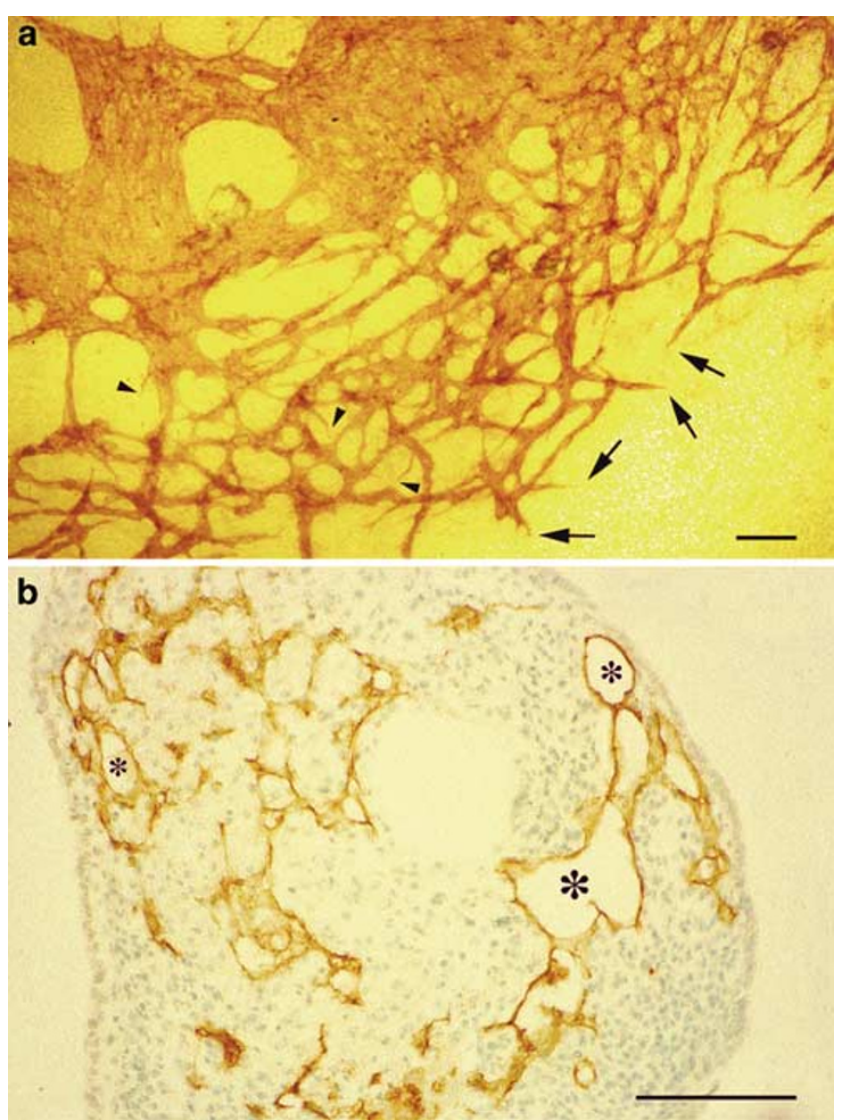

Figure 1 Visualization of vascular structures in CEB by staining for PECAM-1. (a) An attached day 16 CEB showing vascular cords and networks. The growing fronts of the vascular networks (arrows) as well as remodeling (arrow heads) within the vascular cords are clearly visible. (b) A section of a day 19 'floating' CEB showing endothelial cell-lined channels $\left({ }^{*}\right)$. Bars $=200 \mu \mathrm{m}$.

obtained using a VEGF isoform-specific ribonuclease protection assay (data not shown), which also indicated that VEGF164 is the predominant VEGF mRNA isoform expressed by differentiating CEB. Expression of VEGF receptor 2 (VEGFR2/ Flk-1), a high-affinity receptor for VEGF, also commenced on day 4 of CEB differentiation as determined by RT-PCR analysis (Figure 3c). Thus, VEGF expression during CEB differentiation correlates temporally with the expression of its primary signaling receptor, VEGFR2.

Elevated VEGF mRNA levels have been shown in a number of systems to be mediated at the level of increased mRNA stability. ${ }^{13,14}$ To determine if mRNA stabilization was playing a role in the elevated VEGF seen during CEB differentiation, VEGF mRNA stability was assessed in CEB that were differentiated for 4 days and longer. Results of these studies indicated that the increase in VEGF mRNA levels in differentiating CEB was not due to an increase in mRNA stability (Figure 4). The halflife of VEGF mRNA in CEB was less than $2 \mathrm{~h}$, which compares well with that reported for VEGF mRNA 

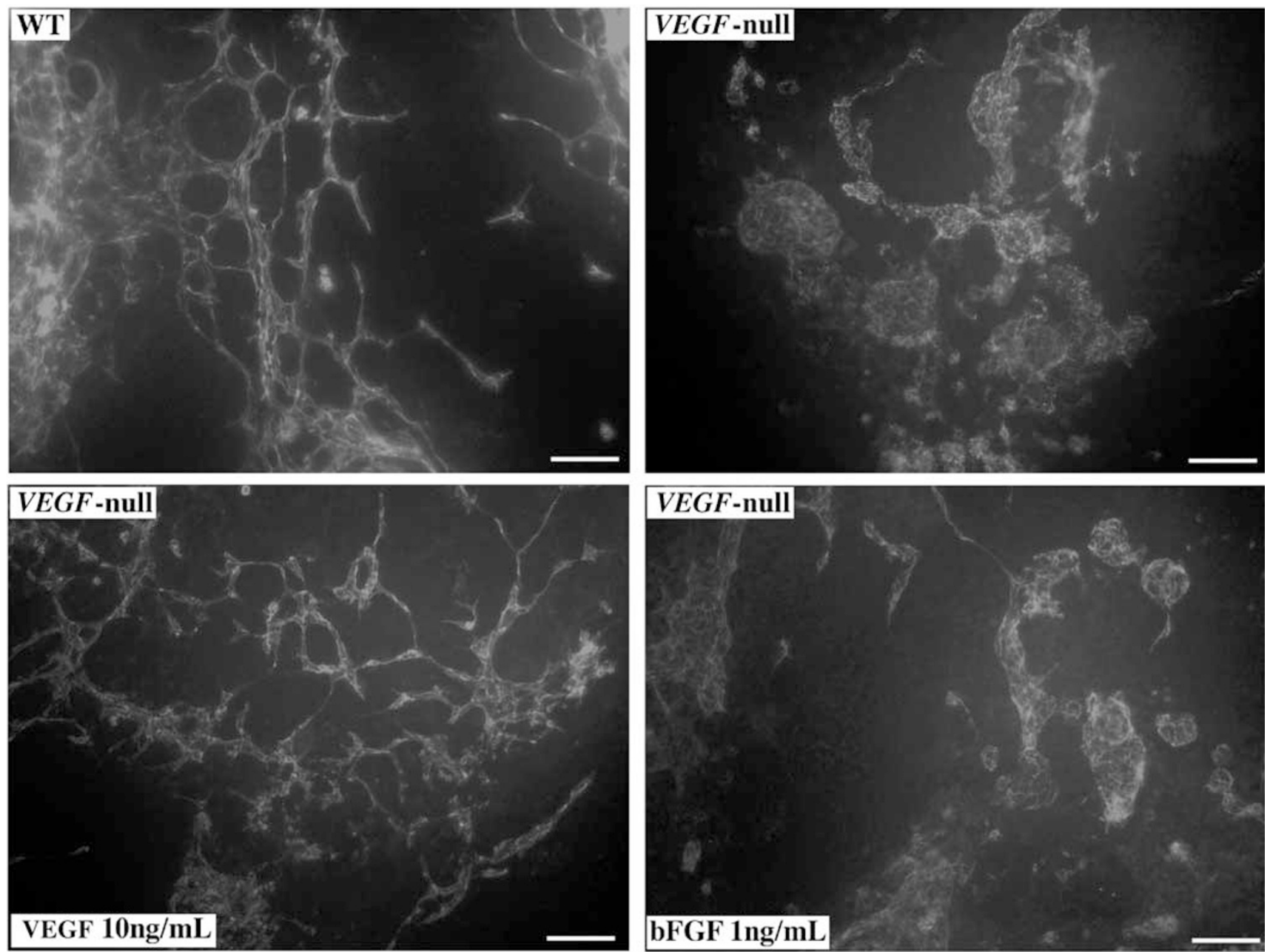

Figure 2 Effect of exogenous VEGF or FGF-1 on vessel structures in VEGF-null CEB. Top panels: Fluorescent localization of PECAM-1positive vessel structures in CEB formed from wt ES and VEGF-null ES cells. For rescue studies physiological doses of VEGF (10 ng/ml) or bFGF ( $1 \mathrm{ng} / \mathrm{ml}$ ) were added to day 4 CEB, the time when high VEGF expression is first observed in the wt CEB. Bottom panels: Effect of VEGF (left) and bFGF (right) addition on vessel formation in VEGF-null CEB. VEGF rescues the formation of vascular cords and networks in VEGF-null CEB, whereas addition of bFGF promotes the proliferation of EC and enlargement of the endothelial clusters. Bars $=100 \mu \mathrm{m}$

in cells grown under normoxic conditions. ${ }^{13-15}$ Hypoxic stabilization of VEGF mRNA, on the other hand, has been reported to increase the VEGF mRNA half-life to at least $8 \mathrm{~h} \cdot{ }^{13,14}$ Thus, the increase in VEGF mRNA levels during CEB differentiation is unlikely to be due to mRNA stabilization but is rather the result of initiation and/or upregulation of $V E G F$ transcription.

In order to determine if VEGF expression is physically associated with the vascular networks, $V E G F^{\mathrm{LacZ} I+}$ ES cells ${ }^{16}$ were aggregated to form CEB and then used to examine the spatial association between vessel formation and VEGF-synthesizing cells. Using these VEGF $F^{\mathrm{LacZ} /+}$ ES cells, VEGF synthesizing cells can be identified by $\beta$-gal staining. Double labeling of CEB differentiated from $V E G F^{\text {lacZ/ }+}$ ES cells for PECAM- 1 and $\beta$-gal demonstrated a close spatial association between VEGFproducing cells and the forming vascular networks
(Figure 5). Similar results were obtained with two independent lines of $V E G F^{\mathrm{LacZ} /+}$ ES cells (compare Figure $5 \mathrm{a}$ and b). These results suggest that paracrine interactions are involved in the formation of the vessel-like structures observed in CEB.

\section{Identification of Genes Involving in VEGF-Mediated Vascular Morphogenesis}

Our results support the hypothesis that VEGF is required for vascular morphogenesis in the CEB. Therefore, genes that are differentially expressed between the wt CEB (with vessel-like structures) and $V E G F$-null CEB (that lack vessel-like structures) might be involved in vascular morphogenesis. Thus, we used the murine GEM screening technique to identify genes that are differentially expressed between wt and VEGF-null CEB differentiated for 
a
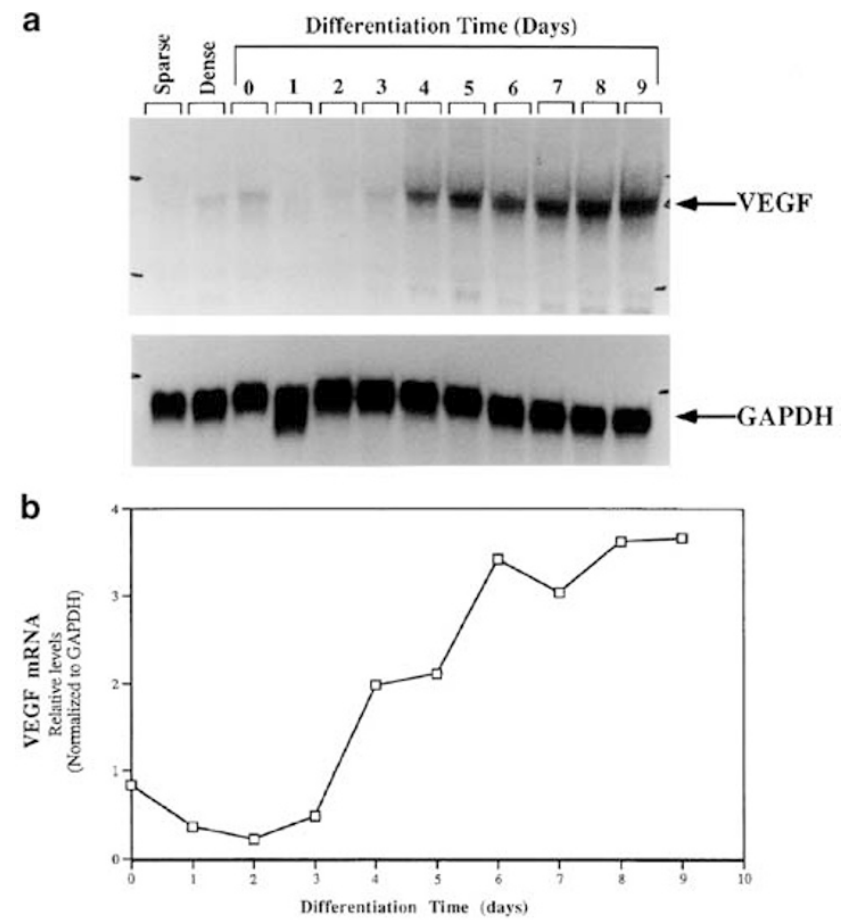

C

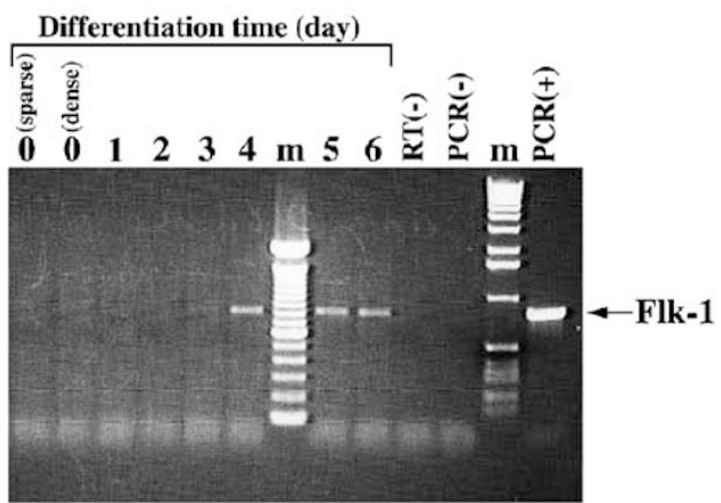

Figure 3 Expression of VEGF and VEGFR2 receptor messages during CEB differentiation. (a) A Northern blot of total RNA isolated from differentiating CEB probed for VEGF expression. Lanes labeled 'sparse' and 'dense' contain total RNA isolated from sparse and dense cultures of undifferentiated ES cells, respectively. (b) Quantitation of VEGF mRNA levels (normalized to GAPDH levels) during CEB differentiation based on the results in (a). Expression of VEGF commenced on day 4 of CEB differentiation, and the levels of VEGF mRNA increased steadily from day 4 to day 9. (c) RT-PCR analysis of total RNA isolated from differentiating CEB for Flk-1 expression showing that the expression of VEGFR2 commenced on day 4 of CEB differentiation. Lane m, size marker. Lane RT(-), the negative control for the $\mathrm{RT}$ reactions in which no reverse transcriptase was added. Lane PCR $(-)$, the negative control for the PCR reactions in which no DNA template was added. Lane PCR $(+)$, the positive control for the PCR reaction, in which $5 \mathrm{ng}$ of VEGFR2 plasmid DNA was used.

10 days (Table 1). A positive balanced differential expression index indicates higher expression by the wt CEB and a negative index reflects higher expression by the VEGF-null CEB. These data

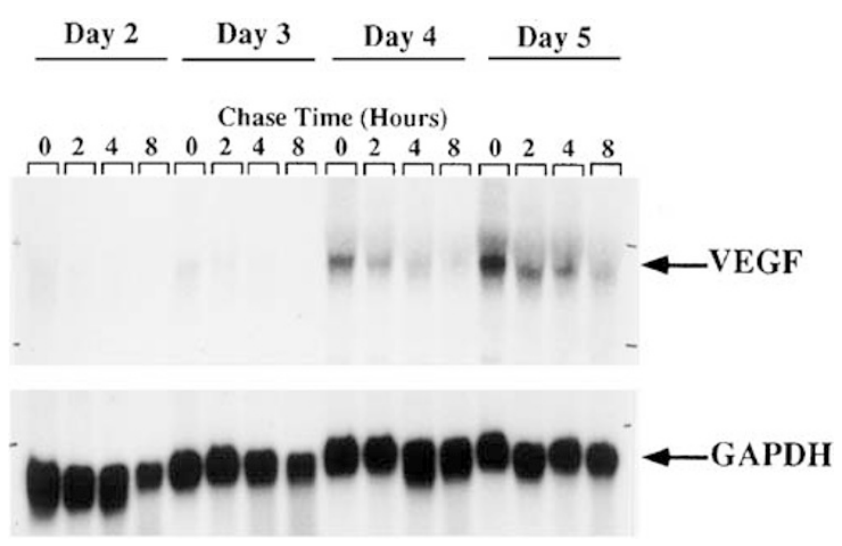

Figure 4 Analysis of VEGF mRNA stability during CEB differentiation. Actinomycin D was added to CEB differentiated for 2, 3, 4 and 5 days, and total RNA was extracted at $0,2,4$ and $8 \mathrm{~h}$ later. The resulting RNA samples were analyzed for the levels of VEGF mRNA by Northern blot analysis. The increase in VEGF mRNA levels in day 4 and older CEB is not due to an increase in VEGF mRNA stability.

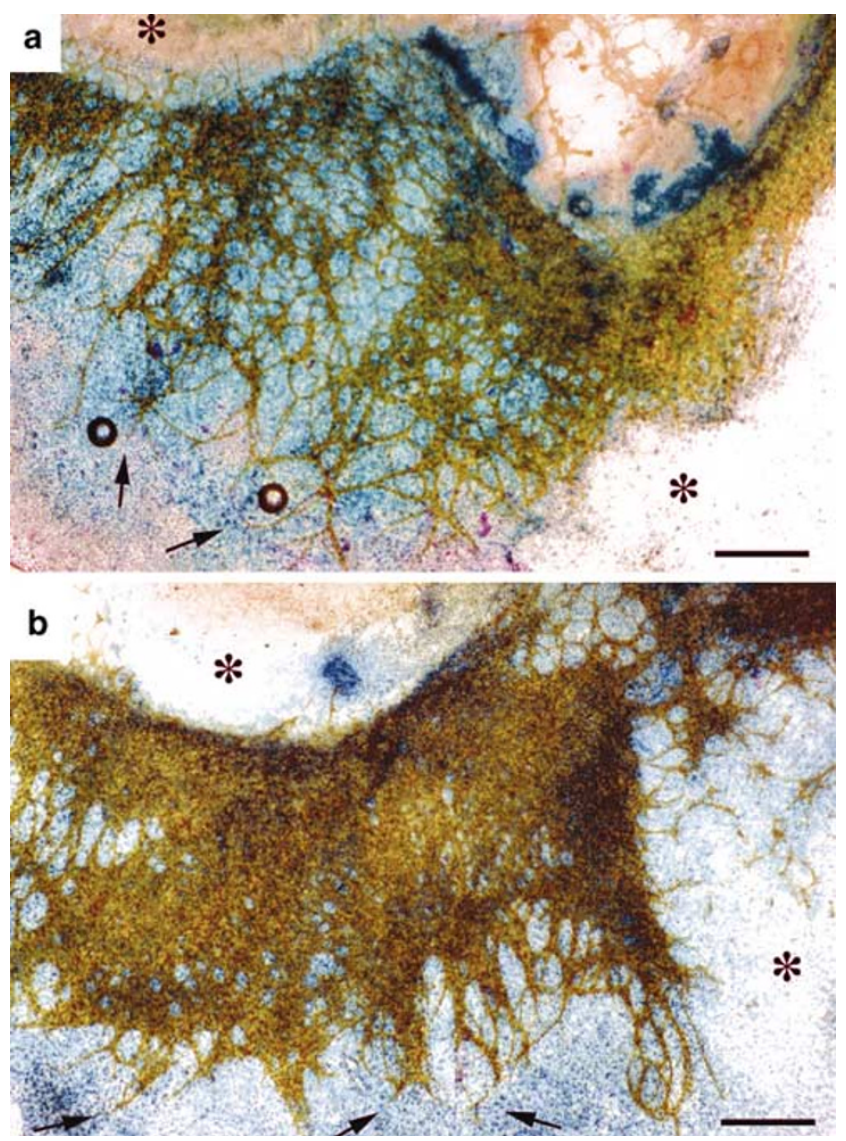

Figure 5 Relationship between VEGF-expressing cells and vascular structures in CEB. Day 35 attached CEB derived from $V E G F^{\mathrm{LacZ} /+}$ ES cells were double stained for PECAM-1 (brown) and VEGF-production (blue), two independently-derived clones are shown (a) \#D10 and (b) \#D11. Growing fronts of the vascular cords/channels are associated with areas of VEGF production (arrows) and do not extend to the areas where VEGF is not expressed (*). Bars $=600 \mu \mathrm{m}$. 
Table 1 Differential genes expression between wt and VEGF-null CEB

\begin{tabular}{|c|c|}
\hline $\begin{array}{l}\text { Balanced } \\
\text { diff exp }\end{array}$ & Gene name \\
\hline 4.1 & Caveolin, caveolae protein, 22 kDa \{IMAGE:596968\} \\
\hline 2.9 & $\begin{array}{l}\text { Mus musculus mRNA for endomucin-1, complete } \\
\text { cds \{IMAGE:890607\} }\end{array}$ \\
\hline 2.2 & $\begin{array}{l}\text { Hairy/enhancer-of-split related with YRPW motif } 1 \\
\text { \{IMAGE:419138\} }\end{array}$ \\
\hline 2 & ESTs \{IMAGE:535794\} \\
\hline 1.9 & ESTs \{IMAGE:407202\} \\
\hline 1.8 & ESTs \{IMAGE:722631\} \\
\hline 1.8 & ESTs \{IMAGE:374240\} \\
\hline 1.7 & Cadherin 5 \{IMAGE:385761\} \\
\hline 1.1 & DNA polymerase alpha 2, $68 \mathrm{kDa}$ \{IMAGE:476123\} \\
\hline 1 & $\begin{array}{l}\text { RNA polymerase 1-3 (16 kDa subunit) } \\
\text { \{IMAGE:403327\} }\end{array}$ \\
\hline 1 & $\begin{array}{l}\text { ESTs, highly similar to PUTATIVE 60S RIBOSOMAL } \\
\text { PROTEIN (Homo sapiens) \{IMAGE:316467\} }\end{array}$ \\
\hline-1 & Pyruvate dehydrogenase 2 \{IMAGE:752497\} \\
\hline-1.7 & $\begin{array}{l}\text { ESTs, highly similar to fibrinogen Beta chain } \\
\text { precursor (Homo sapiens) \{IMAGE:348037\} }\end{array}$ \\
\hline-1.8 & Hemoglobin alpha, adult chain 1 \{IMAGE:571819\} \\
\hline-1.8 & $\begin{array}{l}\text { Transforming growth factor, beta receptor III } \\
\{\text { IMAGE: } 476264\}\end{array}$ \\
\hline-2 & Public domain EST \{IMAGE:482677\} \\
\hline-2.1 & $\begin{array}{l}\text { Platelet-derived growth factor receptor, alpha } \\
\text { polypeptide \{IMAGE:721790\} }\end{array}$ \\
\hline-2.6 & ESTs \{IMAGE:719965\} \\
\hline-3.2 & $\begin{array}{l}\text { ESTs, weakly similar to SPARC-related protein ( } M \text {. } \\
\text { musculus) \{IMAGE:482198\} }\end{array}$ \\
\hline-6.3 & $\begin{array}{l}\text { Mus musculus osf-2 mRNA for osteoblast specific } \\
\text { factor } 2 \text {, complete cds \{IMAGE:403071\} }\end{array}$ \\
\hline-6.7 & Procollagen, type III, alpha 1 \{IMAGE:420322\} \\
\hline-8.5 & Lumican \{IMAGE:746644\} \\
\hline
\end{tabular}

A positive balanced differential expression index indicates higher expression by wt CEB and a negative index reflects higher expression by the VEGF-null CEB.

identified various genes that are associated with normal mature endothelium, such as caveolin and cadherin-5, expressed at higher levels in the wt CEB (eg lower levels in VEGF-null CEB). Higher expression of extracellular matrix proteins, such as lumican and procollagen, were associated with the $V E G F$-null CEB, a possible reflection of less 'mature' endothelium. Importantly, this GEM screening identified numerous ESTs with higher expression levels in the wt CEB than in the VEGF-null CEB; these may represent novel genes downstream of VEGF signaling and may be involved in endothelial branching and vessel morphogenesis. Lastly, genes that would not be expected to differ between the wt and VEGF-null CEB, such as DNA polymerase, RNA polymerase and ribosomal protein, were expressed at similar levels. A majority (97\%) of the genes on the microarray were expressed at comparable levels (balanced differential expression index between 1.4 and 1.4) in both the wt and the VEGF-null CEB (Figure 6). Similar qualitative differences were obtained when day 9 CEB were used in the screening (data not shown).

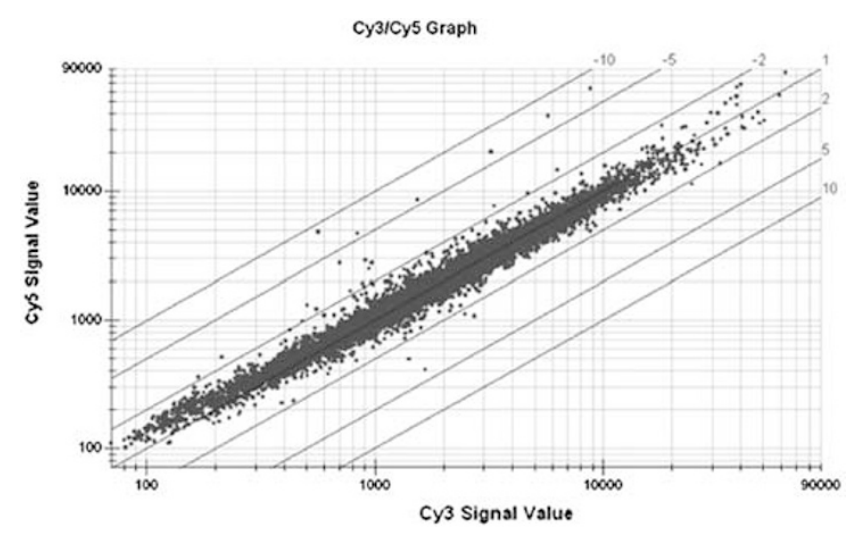

Figure 6 GEM analysis of wt and $V E G F$-null CEB. This signal intensity plot indicates that the expression levels of the majority $(97 \%)$ of the genes are comparable (within 1.4-fold) between wt and VEGF-null CEB.

\section{Validation of the GEM Data}

GEM screening identified several known genes that have been implicated in vascular development, including caveolin, cadherin-5 and Hey-1. ${ }^{17-21}$ In order to confirm the GEM data, semiquantitative RTPCR analysis (data not shown) and immunostaining were used to compare the expression of some of these genes between wt and VEGF-null CEB. Consistent with the microarray data, the levels of caveolin-1 and endomucin-1 were significantly lower in the EC of VEGF-null CEB than in the wt CEB (Figure 7), whereas the levels of PECAM-1 were comparable. These data verify that the genes identified by microarray to be differentially expressed at the mRNA level are also differentially expressed at the protein level.

Knockout analysis has revealed that in addition to $V E G F$, a number of other genes including FGFR-1 and GATA-4 play critical roles during vascular development. Visualization of vessels in CEB formed from ES cells null for FGFR-1 and GATA-4 revealed defects in vessels that were distinct from those observed in VEGF-null CEB (Figure 8). Whereas the absence of VEGF was associated with EC aggregates, CEB derived from FGFR-1-deficient ES cells contained large sheets of EC connected by thin strand-like processes. PECAM-1 staining of CEB derived from GATA-4-deficient ES cells, on the other hand, revealed EC clumps dispersed among rudimentary cord fragments.

\section{Discussion}

Until recently, information regarding the regulation of angiogenesis and vasculogenesis was largely descriptive, and came primarily from classic embryological studies. Over the past decade, the identification of a number of defined molecules critical to normal vascular development, in combination with the ability to manipulate genetically the mouse 

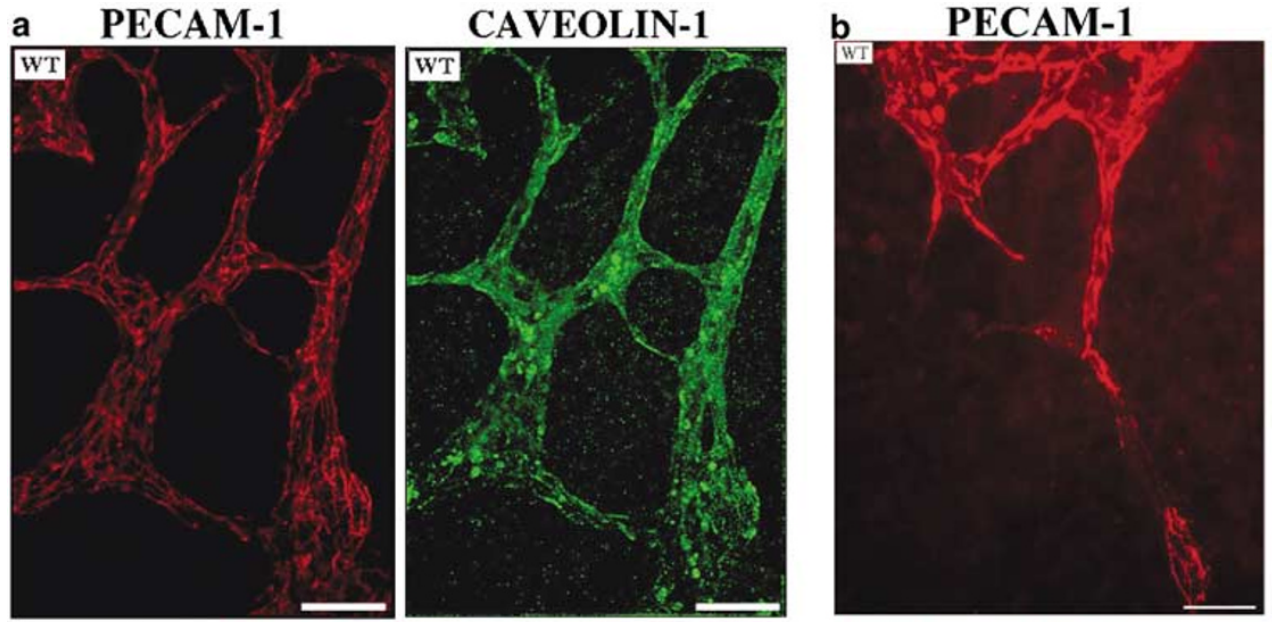

ENDOMUCIN-1
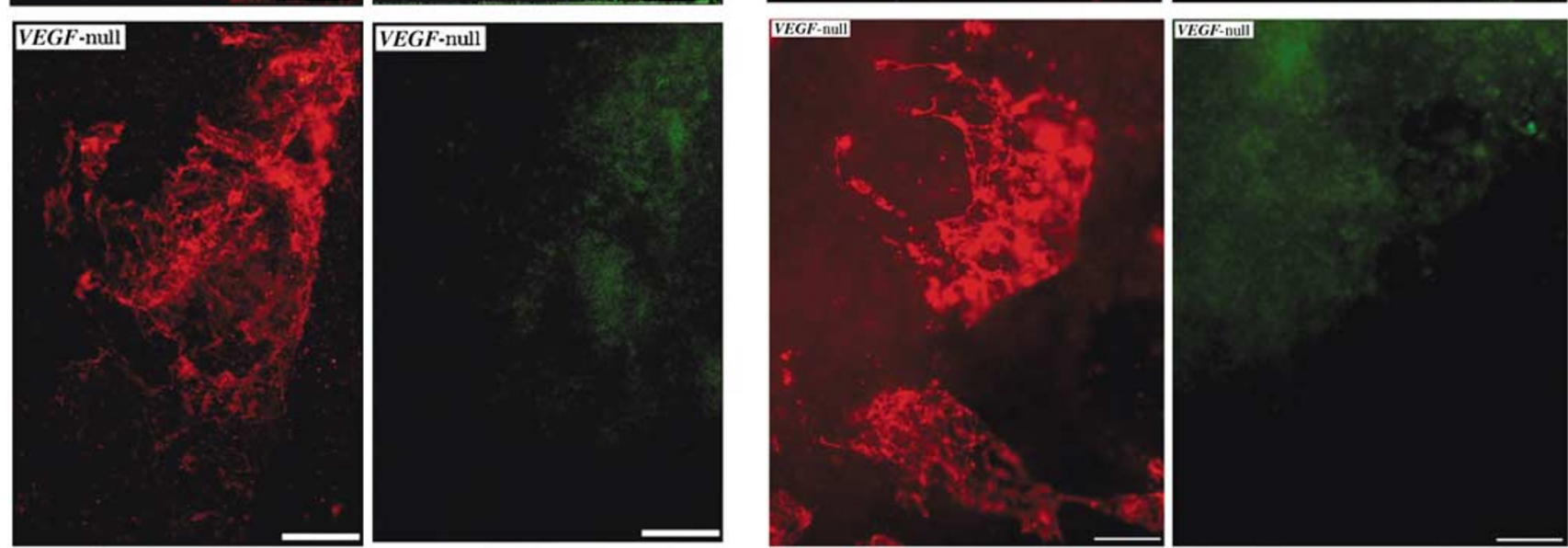

Figure 7 Expression of caveolin-1 and endomucin-1 protein in CEB formed from wt and VEGF-null ES cells. (a) Top panels: Double staining for caveolin-1 protein (green) and PECAM-1 protein (red) confirm that caveolin-1 is highly expressed by EC in day 16 wt CEB. Note vesicular nature of the caveolin-1 staining in wt EC. Bottom panels: PECAM-1 staining reveals the presence of EC clusters in VEGFnull CEB and very low levels of caveolin-1 staining. (b) Top panels: Double staining for endomucin-1 protein (green) and PECAM-1 protein (red) in wt CEB show that EC express high levels of endomucin-1. Also note the cell-surface nature of the endomucin-1 staining on wt EC. Bottom panels: The PECAM-1 positive EC cluster (red) in VEGF-null CEB have no detectable endomucin-1 protein staining.
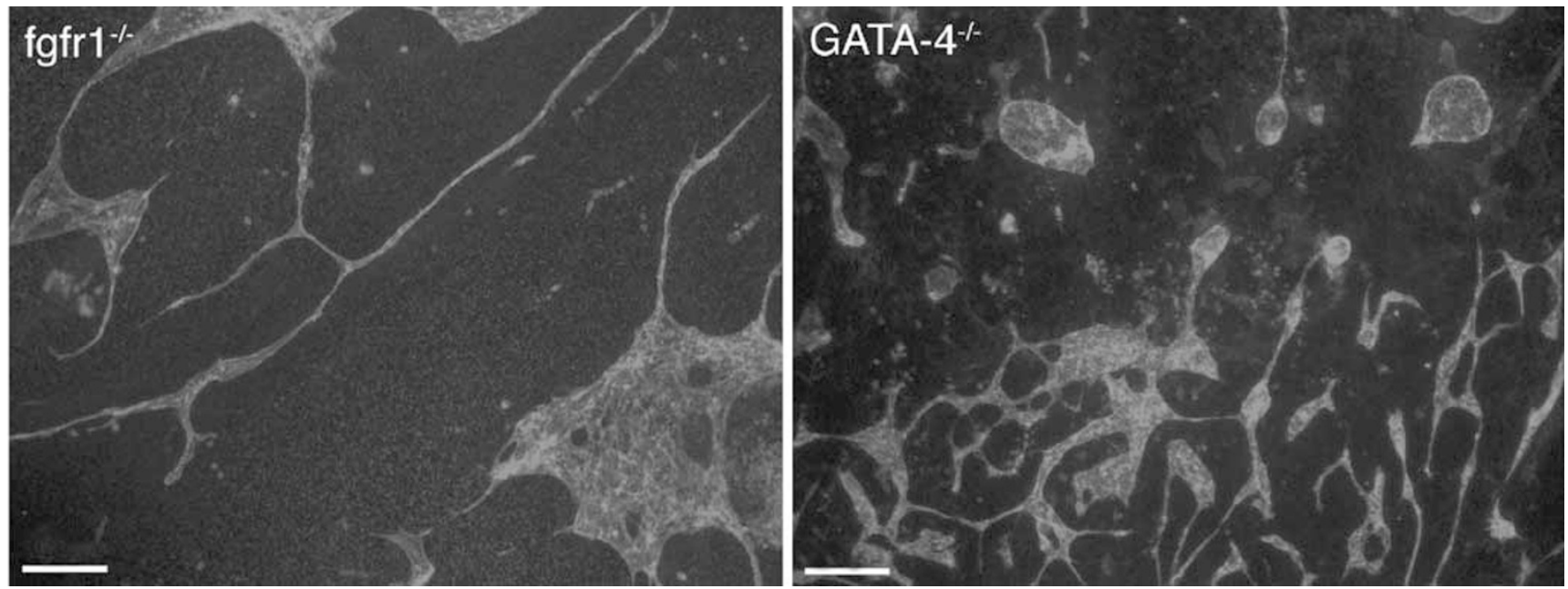

Figure 8 Defective vascular morphogenesis in FGFR-1-null and GATA-4-null CEB. Endothelial localization in FGFR-1-null and GATA-4null CEB by PECAM-1 staining reveals distinct defects in their vessel morphologies as compared to wt CEB (Figures 1 and 2). 
genome by gene knockout, has begun to provide insight into the molecular mechanisms that regulate vessel assembly. However, when inactivation of genes that are critical for vascular development results in early embryonic lethality, the gene targeting approach provides limited insight into a gene's mechanism of action. Use of the CEB system has allowed us to verify the critical role of VEGF in vascular morphogenesis in spite of the fact that haploinsufficiency causes early embryonic lethality. ${ }^{1,2}$ Our results suggest that the expression of VEGF in the CEB is both temporally and spatially correlated with the development of the vascular network. Furthermore, our analysis of the VEGFnull CEB suggests that VEGF expression is necessary for EC branching and morphogenesis. Induction of EC proliferation by bFGF did not rescue vascular morphogenesis, and thus the lack of the mitogenic effects of VEGF in the null CEB does not account for the absence of vessel formation. In addition, the use of VEGF-lacZ ES cells to form CEB revealed a close spatial association between VEGF-producing cells and vascular networks, suggesting that VEGF also plays a role in vascular patterning. This concept is further supported by recent work using mice that express single VEGF isoforms. Mice that express only VEGF 120, which lacks heparan sulfate-binding capacity and thus might not be expected to develop local VEGF gradients, develop abnormal vessels that are characterized by defective branching patterns. $^{22}$

Taking advantage of the observation that EC fail to organize into vascular networks in the VEGF-null CEB, we used the GEM screening to identify genes that may be involved in vascular morphogenesis. Our screening identified several EC-specific and ECselective genes that have been previously implicated in vascular morphogenesis, as well as numerous novel ESTs. The differential expression of calveolin1 and endomucin-1 genes was verified at the protein level by immunostaining of EC in wt and $V E G F$-null CEB.

The functional relevance of these genes in vascular morphogenesis has been suggested by observations in other systems. Caveolin-1 has been reported to be required for EC vascular network formation in a tissue culture model of angiogenesis. ${ }^{17,19}$ Furthermore, caveolin-1-null mice exhibit defective postnatal angiogenesis in response to growth factors and in tumor vascular growth, strongly supporting the hypothesis that caveolin-1 is required for angiogenesis in vivo. ${ }^{18}$

These results strongly suggest that the VEGF-null CEB model is suitable for the identification of genes that are downstream of VEGF signaling, which are likely to be EC-specific or EC-selective and are involved in VEGF-mediated EC morphogenesis. Because of the EC-selective nature of VEGF signaling, the VEGF-null CEB model appears to have conferred a high degree of 'built-in' specificity for identifying genes associated with EC morphogen- esis. The CEB system also offers an opportunity for additional manipulations. For instance, EC could be isolated from the wt and VEGF-null CEB for mRNA extraction for GEM screening. Alternatively, DNA and mRNA microarrays containing EC-specific genes could be used for the screening to achieve higher EC-specificity. Furthermore, the CEB genescreening approach can be easily adapted for other gene knockout ES cells. This should prove especially useful for genes whose inactivation has been shown to cause early embryonic lethality, thus preventing assessment of the effect of the target gene on later aspects of vessel development. For example, $F G F R-1^{23}$ and transcription factor GATA-4 ${ }^{24}$ null embryos suffer from early lethality that prevents detailed studies of their roles in vascularization. Not surprisingly, vascular-specific staining in the FGFR-1-null and GATA-4-null CEB reveal distinct differences in their vessel morphologies. Mechanistic insight into these differences could be gained using GEM microarray screening. In light of the increasing number of genes that have been identified to play an important role in vascular development but that exhibit embryonic lethality, use of the CEB model system of vasculogenesis/angiogenesis should permit identification of downstream effectors of these genes and facilitate the identification of novel genes that are involved in various aspects of vascular development and morphogenesis.

\section{Acknowledgements}

This work was supported by CA45548 (PAD), EY05318 (PAD) and Department of Defense, Army predoctoral fellowship \#DAMD17-01-1-0387 (RMBL).

\section{Duality of Interest}

No duality of interest declared.

\section{References}

1 Carmeliet P, Ferriera V, Breier G, et al. Abnormal blood vessel development and lethality in embryos lacking a single VEGF allele. Nature 1996;380:435-439.

2 Ferrara N, Carver-Moore K, Chen H, et al. Heterozygous embryonic lethality induced by targeted inactivation of the VEGF gene. Nature 1996;380:439-442.

3 Baatout S. Endothelial differentiation using Matrigel. Anticancer Res 1996;17:451-455.

4 Davis G, Camarillo C. An alpha 2 beta 1 integrindependent pinocytotic mechanism involving intracellular vacuole formation and coalescence regulates capillary lumen and tube formation in three-dimensional collagen matrix. Exp Cell Res 1996;10:39-51.

5 Evans M, Kaufman M. Establishment in culture of pluripotential cells from mouse embryos. Nature 1981;292:154-156. 
6 Martin G. Isolation of a pluripotent cell line from early mouse embryos cultured in medium conditioned by teratocarcinoma stem cells. Proc Natl Acad Sci USA 1981;78:7634-7638.

7 Krah K, Mironov V, Risau W, et al. Induction of vasculogenesis in quail blastodisc-derived embryoid bodies. Dev Bio 1994;164:123-132.

8 Risau W, Sariola H, Zerwes HG, et al. Vasculogenesis and angiogenesis in embryonic-stem-cell-derived embryoid bodies. Development 1988;102:471-478.

9 Bautch VL, Stanford WL, Rapoport R, et al. Blood island formation in attached cultures of murine embryonic stem cells. Dev Dyn 1996;205:1-12.

10 Desbaillets I, Ziegler U, Groscurth P, et al. Embryoid bodies: an in vitro model of mouse embryogenesis. Exp Physiol 2000;85:645-651.

11 Feraud O, Cao Y, Vittet D. Embryonic stem cell-derived embryoid bodies development in collagen gels recapitulates sprouting angiogenesis. Lab Invest 2001;81: 1669-1681.

12 Dieffenbach C, Dveksler G. PCR Primer: A Laboratory Manual. Cold Spring Harbor Laboratory Press: New York, 1995.

13 Shima DT, Deutsch U, D'Amore PA. Hypoxic induction of vascular endothelial growth factor (VEGF) in human epithelial cells is mediated by increases in mRNA stability. FEBS Lett 1995;370:203-208.

14 Ikeda E, Achen MG, Brier G, et al. Hypoxia-induced transcriptional activation and increased messenger RNA stability of vascular endothelial growth factor in C6 glioma cells. J Biol Chem 1995;270:9761-9766.

15 Stein I, Neeman M, Shweiki D, et al. Stabilization of vascular endothelial growth factor mRNA by hypoxia and hypoglycemia and coregulation with other ischemia-induced genes. Mol Cell Biol 1995;15:5363-5368.
16 Miquerol L, Gertsenstein M, Harpal K, et al. Multiple developmental roles of VEGF suggested by a LacZtagged allele. Dev Biol 1999;212:307-322.

17 Griffoni C, Spisni E, Santi S, et al. Knockdown of caveolin-1 by antisense oligonucleotides impairs angiogenesis in vitro and in vivo. Biochem Biophys Res Commun 2000;276:756-761.

18 Woodman SE, Ashton AW, Schubert W, et al. Caveolin1 knockout mice show an impaired angiogenic response to exogenous stimuli. Am J Pathol 2003;162: 2059-2068.

19 Liu J, Wang XB, Park DS, et al. Caveolin-1 expression enhances endothelial capillary tubule formation. J Biol Chem 2002;277:10661-10668.

20 Rahimi N, Kazlauskas A. A role for cadherin-5 in regulation of vascular endothelial growth factor receptor 2 activity in endothelial cells. Mol Biol Cell 1999;10:3401-3407.

21 Henderson AM, Wang SJ, Taylor AC, et al. The basic helix-loop-helix transcription factor HESR1 regulates endothelial cell tube formation. J Biol Chem 2001; 276:6169-6176.

22 Ruhrberg C, Gerhardt H, Golding M, et al. Spatially restricted patterning cues provided by heparin-binding VEGF-A control blood vessel branching morphogenesis. Genes Dev 2002;16:2684-2698.

23 Deng C, Bedford M, Li C, et al. Fibroblast growth factor receptor-1 (FGFR-1) is essential for normal neural tube and limb development. Dev Biol 1997;185: $42-54$.

24 Soudais C, Bielinska M, Heikinheimo $\mathrm{M}$, et al. Targeted mutagenesis of the transcription factor GATA-4 gene in mouse embryonic stem cells disrupts visceral endoderm differentiation in vitro. Development 1995;121:3877-3888. 